\title{
| EDITORIAL
}

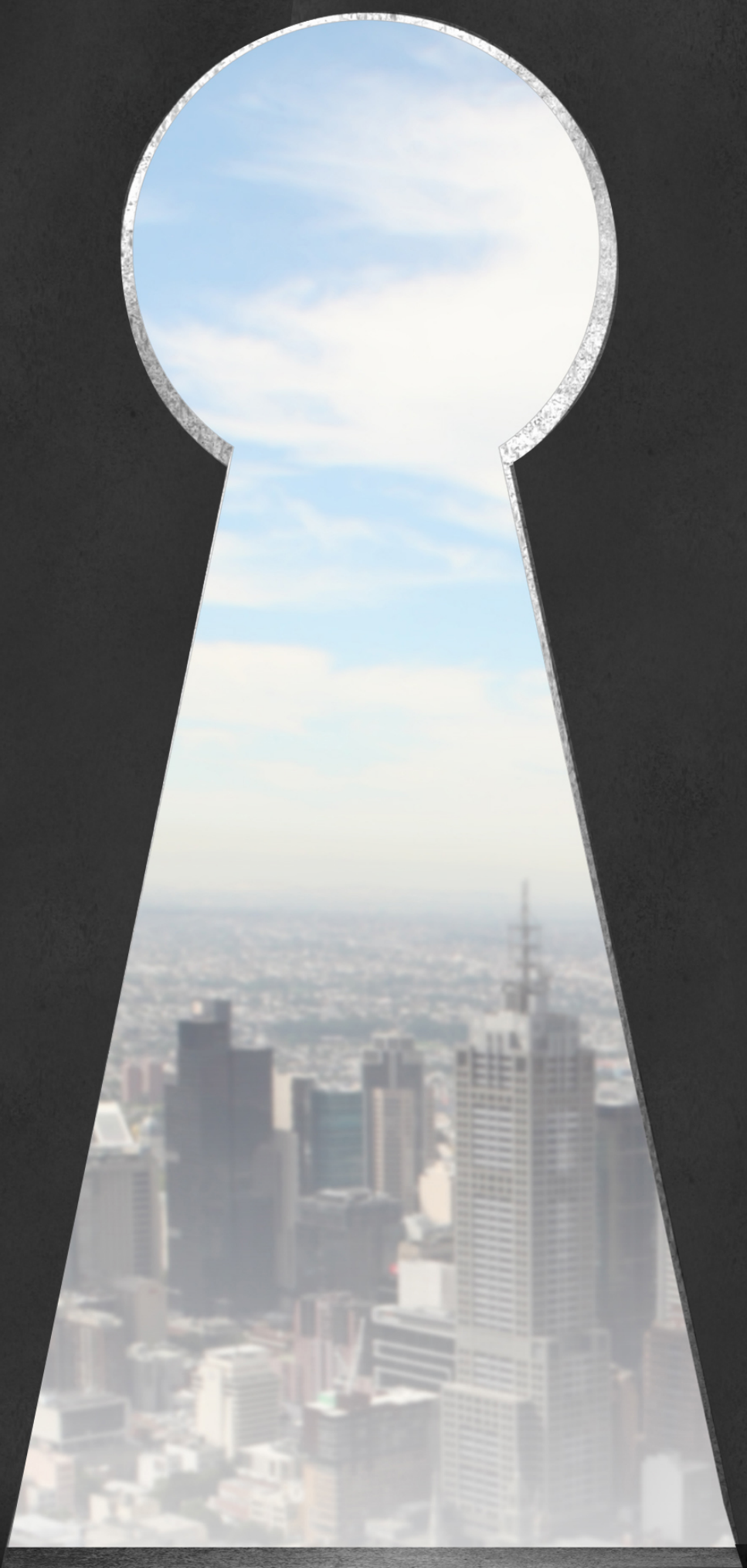




\section{EXPANDINDO HORIZONTES}

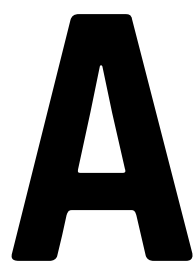

primeira edição deste ano traz um caderno especial com quatro artigos que mostram o potencial de cooperação ainda inexplorado nas relações Brasil-Índia. No primeiro artigo, Umesh Mukhi apresenta caminhos inovadores para a colaboração governamental, educacional e cultural entre os dois países como forma de o Brasil ampliar outro grande mercado além da China. Tales Andreassi e Umesh Mukhi tratam de um tema pouco debatido nas corporações, o amor nas organizações, e mostram, com base em pesquisas científicas e estudos de casos da Índia, como uma cultura de coesão pode trazer vantagem competitiva. O artigo de Sanjay Lanka discute os benefícios de uma agricultura sustentável, por meio da experiência de uma cooperativa de café na Índia. Finalmente, o artigo de Luiz Carlos Catirse descreve como a ioga, uma prática indiana milenar, faz diferença em presídios em São Paulo e no mundo todo.

Quatro outros artigos sobre temas diversos compõem este número, trazendo uma visão crítica sobre temas atuais da gestão. Américo Rodrigues de Figueiredo, em Gestão baseada em evidências, critica a superficialidade e as pirotecnias dos posts no LinkedIn, que trazem modismos, clichês e frases de efeito sem impacto nos resultados, e sugere quatro fontes de evidências - pesquisas científicas, informações das próprias empresas, experiência profissional e valores - para balizar as decisões nas organizações. Em consonância com esse momento de celebridades, Benjamin Rosenthal analisa como as pessoas viram marcas, baseado em estudos recentes na área de marketing. Vítor da Cunha Silveira, em O que é inovação disruptiva, mostra como o termo vem sendo usado de forma inapropriada, o que pode levar a prescrições inadequadas de gestão. Já Fernando Burgos, em $O s$ idosos na agenda governamental, defende que é necessário mudar as políticas públicas para considerar a heterogeneidade da crescente população brasileira com mais de 65 anos.

Completam a edição a coluna Economia, de Paulo Sandroni, que apresenta questões pouco tratadas na indústria da construção civil; a coluna Sociedade e Gestão, de Renato Guimarães Ferreira, sobre o caminho do autoconhecimento inspirado pelo centenário de Clarice Lispector; a coluna Gestão, de Marina Gama e Jeferson Lana, a respeito da presença de políticos em conselhos de administração; e a coluna Empreendedorismo, de Gilberto Sarfati, acerca de conflitos afetivos em startups.

Trazemos ainda a entrevista com Dennis Wang, que fez parte da alta gerência da Easy Taxi e do Nubank e revela como resolveu o dilema de trabalhar em grandes empresas ou em startups. Além disso, ele enfatiza a importância de períodos sabáticos para redirecionar a carreira.

Por diferentes perspectivas, os artigos, as colunas e a entrevista desta edição mostram que, afinal, para uma boa gestão é preciso expandir horizontes. Contam nesse caminho com pessoas e afetos envolvidos nas relações profissionais, assim como com pesquisas científicas para a tomada de decisão bem fundamentada.

Boa leitura.

Maria José Tonelli - Editora chefe

Adriana Wilner - Editora adjunta 